\title{
INTERCULTURAL INTERACTIONS AT MULTINATIONAL CORPORATIONS' WORKPLACE: GROUNDED THEORY
}

\author{
Małgorzata Rozkwitalska ${ }^{a}$, Beata A. Basińska, \\ Michat Chmieleckic, Sylwia Przytuła ${ }^{\text {, Eukasz Sułkowski }}$
}

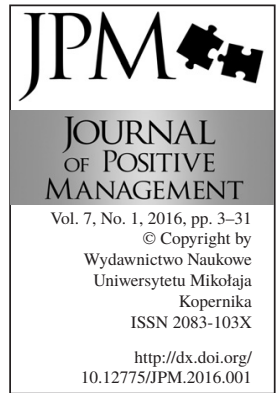

${ }^{\text {a } W S B ~ U n i v e r s i t y ~ i n ~ G d a n s k, ~ G d a n s k, ~ P o l a n d ~}$

${ }^{\mathrm{b}}$ Gdansk University of Technology, Gdansk, Poland

${ }^{c}$ University of Social Sciences, Lodz, Poland

${ }^{\mathrm{d}}$ Wroclaw University of Economics, Wroclaw, Poland

${ }^{\mathrm{e}}$ University of Social Sciences, Lodz, Poland
ae-mail: mrozkwitalska@wsb.gda.pl
be-mail: bbas@pg.gda.pl
ce-mail: mchmielecki@ spoleczna.pl
de-mail: s_przytula@wp.pl
ee-mail: lsulkowski@spoleczna.pl

\begin{abstract}
Purpose: Due to globalization and the global mobility of workforce, working in multicultural environments is a new challenge for employees and managers. The aim of the paper is to analyze the social interactions in multicultural environments of multinational corporations (MNCs) as well as to propose a model of intercultural social interactions in MNCs' specific context.
\end{abstract}

Design/methodology/approach: The grounded theory approach was applied to create a model of intercultural interactions in MNCs. The data was obtained during the qualitative research based on comparative case studies collected in 5 MNCs' subsidiaries.

Findings: The proposed model refers to the following concepts: 1) Lazarus's transactional stress theory states that job demands may be assessed as hindrances or challenges. The specific job demands that affect intercultural interactions are multilingualism, cultural diversity, cross-cultural adjustment and team work. 2) Positive psychological capital and an individual's acquired resources are in relation with intercultural interactions. 3) According to Bandura's agentic perspective, individuals take an active role in shaping social interactions and work environment. 4) Being an agent relates to Spreitzer's thriving concept that can serve as a mechanism of relations between the interactions undertaken due to MNCs' specific job demands and their outcomes.

Research limitations/implications: The qualitative methodology applied to the research does not allow for a broader generalization of the results. The outcomes of intercultural interactions depend mainly on how individuals assess their job demands in MNCs.

Practical implications: Since the workplace in MNCs is abundant in learning opportunities, the managers of MNCs need to hire employees who exhibit needs for growth and development to boost thriving in their organizations. Additionally, these managers should search for employees with experience of multicultural settings and a significant capacity of positive psychological capital, 
INTERCULTURAL INTERACTIONS AT MULTINATIONAL

Małgorzata Rozkwitalska Beata A. Basińska Michał Chmielecki Sylwia Przytuła Lukasz Sułkowski thanks to which they are likely to benefit more from intercultural social interactions. More concern should be put on training the employees' language skills since it may build their self-efficacy in intercultural interactions.

Originality/value: The proposed model focuses on social interactions in MNCs' unique context. The empirical findings were interpreted with regard to psychological and sociological theories and the Positive Organizational Scholarship lens.

Keywords: intercultural interactions, cultural diversity, multilingualism, agent, thriving, positive psychological capital

Paper type: Research paper

\section{Introduction}

Due to globalization and the global mobility of workforce, working in multicultural environments is a new challenge for employees and managers (Molinsky, 2007; Youssef and Luthans, 2012; HRM spreads word to the world, 2012). In multicultural work environments people interact with others whose national cultural backgrounds differ, overlap and even intertwine (Darawong and Igel, 2012). This factor has potential to create both challenges or barriers (Graham, 2010; White et al., 2011; Lauring and Klitmøller, 2014) and opportunities (Pettigrew and Tropp, 2008; Stahl et al., 2010; Rozkwitalska et al., 2014) for those involved in intercultural interactions.

The interactions among individuals in multicultural work environments are a peculiar type of work social interactions that reflect a dynamic sequence of human actions (Przytuła et al., 2014), in which behaviors of individuals are constantly modified as they react accordingly (Molinsky, 2007). In cross-cultural settings the cultural lens provides a base for interpretation of the behavior of the other party (Webb and Wright, 1996), nevertheless a specific interaction and its outcomes may also be influenced by a given work context (Müller, 1998; Cooper et al., 2007). The work context analyzed in this paper with regard to social interactions is the workplace in multinational corporations (MNCs). It varies from any other corporations' work context as employees in MNCs encounter, among other issues, a cultural and language diversity while performing their duties (Lauring, 2009; Tanova and Nadiri, 2010; Lauring and Selmer, 2011). Hence, the authors' aim is to analyze the social interactions in multicultural environments of MNCs as well as to propose a model of intercultural social interactions in MNCs' specific context.

There is recognition within the fields of international business, international management or cross-cultural (intercultural) management what the outcomes of cultural diversity are. Ample literature and research document both problems witnessed in interactions among culturally diverse individuals and potential positive effects (e.g. McMillan-Capehart, 2005; Cooper et al., 2007; Stahl et al., 
2009; Stahl et al., 2010; Roberge and van Dick, 2010). Numerous studies have also scrutinized the characteristics and skills necessary to function effectively in multicultural environments such as intercultural (cross-cultural) competence, cultural intelligence or intercultural effectiveness (e.g. Fisher and Härtel, 2006; Johnson et al., 2006; Ang et al., 2007; Spitzberg and Changnon, 2009; Panggabean et al., 2013). The researchers have referred mainly to the following theories while exploring the outcomes of cultural diversity and their antecedents, namely social identity theory further substantiated by the similarity-attraction paradigm, information-processing theory, social capital theory and intergroup contact theory (e.g. Loh et al., 2009; Noorderhaven and Harzing, 2009; Roberge and van Dick, 2010; Stahl et al., 2010; White et al., 2011).

Notwithstanding the richness of literature on cultural diversity, some irregularities have been observed concerning the outcomes of interactions among culturally diverse individuals (Mannix and Neale, 2005; Stahl et al., 2010). Moreover, Stahl et al. (2010) claim that the prior research is biased and "the problem-focused view of cultural diversity is by far predominant in research" (Stahl and Tung, 2014). Stahl and Tung prove that much less is known about the positive dynamics and outcomes of intercultural contacts than about the problems. Thus, more work is needed to delve into the positive phenomena by applying "rigorous and systematic investigation" (Stahl et al., 2010). Further, Shore et al., (2009) contend that "scholars need to move beyond old paradigms and limited ways of thinking to develop integrative and practical diversity theories that help organizational leaders create systems in which diverse human beings are able to thrive". Additionally (Shore et al., 2009) notice that "researchers need to shed more light on how people with different nationalities work together to achieve their collective goals", especially that cultural diversity "potentially poses greater challenges when compared with ethnicity" or other diversity sources" because cultural differences (...) among team or organizational members tend to be larger". Likewise social interactions are shaped by a context, "there appear to be contextual elements both outside the organization and inside the organization that may influence the prevalence and impact of diversity" (Shore et al., 2009). Thus, each emergent theory should take into account a specific context.

In this study the authors attempt to respond to the aforementioned calls of the researchers. First and foremost, it is important because the proposed model focuses on social interactions in MNCs' unique context. Second, as the grounded theory approach was adopted to analyze the data, the constructed model of intercultural interactions at MNCs' workplace is embedded in the gathered field data. Such a qualitative study may be important since it allows for "a fuller understanding of (...) cross-cultural dynamics" (Stahl and Tung, 2014), especially that the vast majority of the previous research has taken a quantitative design (Stahl and Tung, 2014). Third, the empirical findings were interpreted with regard to psychological

INTERCULTURAL INTERACTIONS AT MULTINATIONAL

Małgorzata Rozkwitalska Beata A. Basińska Michał Chmielecki Sylwia Przytuła Łukasz Sułkowski 
INTERCULTURAL INTERACTIONS AT MULTINATIONAL

Małgorzata Rozkwitalska Beata A. Basińska Michał Chmielecki Sylwia Przytuła Lukasz Sułkowski and sociological theories and the Positive Organizational Scholarship lens. Fourth, the model appears to be more holistic and integrative than the previous theories because it focuses on potential outcomes of intercultural interactions and their determinants. Finally, the authors' intention was also to build a grounded theory of intercultural interactions that would strive to explain inconsistency in the prior research with respect to the outcomes of cultural diversity.

The research methodology that follows first delineates the research aim and methods. Then, the companies and the participants are portrayed followed by the results and discussions that consult the exiting theories to lay foundations for the authors' grounded theory of intercultural interactions at MNCs' workplace. Afterwards, conclusions that are drawn indicate contributions, limitations and implications of this study. Finally, the authors outline directions for future research.

\section{Methodology}

\subsection{Research aim and methods}

In the paper the authors report the empirical findings of an explorative, qualitative study carried out in the year 2014 and aimed at analyzing intercultural interactions in subsidiaries of MNCs. Both the outcomes of intercultural interactions and the factors necessary to establish successful contacts with the representatives of different cultures in multicultural environments of MNCs have been investigated. Due to the study's focus on how people behave in specific context of MNCs, the grounded theory approach has been applied to analyze the collected field data (Goulding, 1998; Corbin and Strauss, 2008). Thus the theory emerging process began with no previous theory or propositions to verify (Hassi et al., 2011; Randall and Mello, 2012), while the authors' goal was to build a theory of intercultural interactions at MNCs' workplace that could be later tested with quantitative tools (Randall and Mello, 2012). Nonetheless, the empirical findings were also interpreted, as allowed by the grounded theory approach (Goulding, 1998; Kempster and Parry, 2011; Brien and Smallman, 2011; Randall and Mello, 2012), with regard to organizational, psychological and sociological theories to better explain and contextualize them within the emerging model of intercultural interactions. Furthermore, grounded theory appears to be relevant for studying the phenomenon in its unique context (Kempster and Parry, 2011), in this paper in multicultural environments of MNCs.

In congruence with grounded theory, the methodology of the research started with semi-structured, in-depth individual interviews based on a rather loose structure of open-ended questions (Goulding, 1998; Glaser and Strauss, 1999), which were aimed at exploring intercultural interactions of the interviewees. The planned structure of the interview was divided into four sections, yet the order of the questions asked could be modified depending on the course of each 
conversation and relevance of the information obtained (Dearnley, 2005). The first section referred to the characteristics of the interviewee's job position, including his/her intercultural relationships at the workplace. The second part contained questions concerning identification of the positive and negative outcomes of intercultural interactions, whereas the third one tackled an issue of what conditions fruitful cooperation with people from other cultures. The last section comprised the interviewees' particulars. All the interviews were carried out by the authors. The informants were both managers and specialists employed in subsidiaries of MNCs, who, due to their job demands, participated in interactions with representatives of different cultures, usually on a daily basis. The duration of each interview ranged from 45 to 90 minutes, in total there were about 62 hours of interviews with an average time of 55 minutes. The authors conducted them in the companies' offices.

Each interview was transcribed, manually coded, analyzed and constantly compared with one another by the researchers who followed the three-step procedure of analysis to meet the requirements of the grounded theory approach (Hassi et al., 2011; Sánchez Bengoa et al., 2012). Firstly, the open coding was implemented to the data analysis, where the researchers were looking for common themes (keywords, phrases) emerging from the interviews (Randall and Mello, 2012). The initial identified categories were for example broader perspectives, diverse viewpoints or different approaches. During the second step, namely axial coding, those categories were labeled with the higher-level concepts. The categories/concepts identified in this step concerned various types of problems encountered in mutual relationships with foreigners (e.g. conflicts, process loses, communication barriers), positive effects obtained from cooperation (e.g. learning, personal growth, needs fulfillment) and factors that enable beneficial interactions (e.g. openness, language fluency, personality). In the final step of selecting coding, the categories were integrated and refined consequently leading to the emergence of a theoretical scheme used in the paper to discuss the findings. Those categories are specific job characteristics in MNCs, outcomes of intercultural demands, and finally personal resources along with international experience. Memos were used during the whole research process to further the analysis of the data and foster the plausible theoretical framework (Caprar, 2011; Hassi et al., 2011).

The field study carried out by the authors entailed, except for aforementioned in-depth interviews, additional semi-structured interviews with the representatives of the board of directors in the selected subsidiaries, observations of managers during office visits and analysis of the MNCs' documents and their web sources. Since the researchers tried to employ multiple methods of data collection (such as in-depth interviews, observation and document analysis) and diverse sources to obtain datum within a given method (i.e. both specialists and different level managers from various organizational units were interviewed, 59 Poles and 11
INTERCULTURAL INTERACTIONS AT MULTINATIONAL

Małgorzata Rozkwitalska Beata A. Basińska Michał Chmielecki Sylwia Przytuła Łukasz Sułkowski 
INTERCULTURAL INTERACTIONS AT MULTINATIONAL

Małgorzata Rozkwitalska Beata A. Basińska Michał Chmielecki Sylwia Przytuła Lukasz Sułkowski
Table 1.

A brief profile of the subsidiaries foreigners, including a few expatriates that constituted the sample), methodological and data triangulation in the study was attained (Maxwell, 2005).

\subsection{Companies and participants}

Five subsidiaries of MNCs located in Poland, i.e. two German subsidiaries, two North-American and Indian one - each of various sector belonging (see Table 1), were selected via a purposive sampling technique.

Subsidiary B was set by an American multinational semiconductor manufacturer in 1994 as a greenfield investment. Afterwards, the parent enterprise acquired a Scandinavian affiliate located in Poland and in 1999 combined both companies into one subsidiary B. It is primarily organized as an IT-shared service center and its services are available in Europe, the Middle East and Africa (so-called EMEA region). The headquarters also located the HR-shared service center for the EMEA region as well as the global tax and trade shared service center in subsidiary B. The intercultural interactions in the subsidiary refer to rather intense, daily, indirect, virtual relationships with the other employees of the MNC, including members of geographically dispersed multicultural teams who frequently represent culturally distant countries.

Subsidiary C was acquired by an Indian MNC in 2007. It specializes in Business Process Outsourcing and Information Technology Outsourcing and mainly operates on European markets. Subsidiary C was also established as a center of excellence for the corporation in the EMEA region. The subsidiary's staff is involved in both direct and indirect intercultural interactions with foreign clients, contractors and teammates of multicultural virtual teams.

Subsidiary D was founded by an American MNC in 2010. It offers management consulting services for primarily Polish public sector. Its parent company has a ra-

D ther narrow international presence, if compared to the other subsidiaries in the sample. The subsidiary's staff is involved in rather indirect intercultural contacts with the employees and superiors of other MNC's affiliates, while direct interactions refer to relationships with the board of directors. 


\begin{tabular}{ll}
\hline Subsidiary & Description \\
\hline & Subsidiary E is a part of a large German manufacturer that specializes in automotive \\
and industrial products, technology and services for business clients and private \\
customers. The MNC has a broad worldwide presence. It also owns five other af- \\
filiates in Poland. Subsidiary E started its operation in 1991 and was erected via \\
a greenfield investment. It produces and sales automotive equipment and household \\
appliances. With regard to the subsidiary, the intercultural interactions encompass \\
internal direct and indirect contacts with the employees of the other affiliates of \\
the MNC and its headquarters as well as relationships with foreign superiors and \\
contractors.
\end{tabular}

The researchers obtained the MNCs' official consents for conducting the research, which stipulated that they are not allowed to collect, disclose or publish any information that would identify a particular employee or the company as the source of the specific data. Although the interviewees were pointed out by their companies, the participation in the research was on voluntary basis and the subjects' consent was granted in writing.

Seventy interviews with the subsidiaries' staff involved in intercultural interactions at work were carried out by the researchers. The participants were both managers and specialists who accounted for $53 \%$ and $38.2 \%$ of the sample respectively. Although the subjects represented various functional units, $30.9 \%$ of them were employed in operational departments in their respective subsidiaries. The respondents had had international experience (Takeuchi and Chen, 2013 provides an overivew of the various measures of international experience), which could have affected their notion of intercultural interactions. First and foremost, $73.5 \%$ and $75.0 \%$ of the interviewees respectively had worked abroad or lived abroad. Moreover, the majority of them (57.4\%) had worked for MNCs before their present job. The genders' distribution in the sample was equal. As far as nationality is concerned, the sample was mostly composed of Poles (85.3\%) in their twenties and thirties, $42.6 \%$ and $33.8 \%$ respectively (see Appendix 1).

\section{Results}

In order to avoid provoking the participants' negative or positive attitudes to the phenomenon of intercultural interactions and to allow the theory to emerge, at the very beginning of the interviews they asked about the interviewee's first association concerning working relationships with the representatives of different countries. The analysis of the responses to this initial question revealed that multicultural environments of MNCs generate specific job requirements (see par. 3.1) and outcomes for their employees and their organizations (see par. 3.2) as well as motivate people to use and develop their unique personal and acquired resources (see par. 3.3). The same categories loomed up later too, when all the
INTERCULTURAL

INTERACTIONS AT MULTINATIONAL

Małgorzata Rozkwitalska

Beata A. Basińska

Michał Chmielecki Sylwia Przytuła Łukasz Sułkowski

Table 1. continue 
INTERCULTURAL INTERACTIONS AT MULTINATIONAL

Małgorzata Rozkwitalska Beata A. Basińska Michał Chmielecki Sylwia Przytuła Łukasz Sułkowski transcribed data from the entire interviews was compared with one another and refined.

\subsection{Specific job characteristics in multinational corporations}

Constant comparisons of the participants' responses enabled the authors to identify the first category of the emerging theory, namely special job demands in MNCs. As the analysis shows, the informants noticed such job characteristics in MNCs that were categorized by them either as barriers or challenges:

[The barriers to intercultural interactions] are language and time differences that cause communication impediments. Cultural/social differences aren't so noticeable, however they mean e.g. other days off in a subsidiary and the headquarter, which to certain degree can be troublesome for global teams. [As the barrier] I would also mention the lack of awareness/understanding of the local law.

My first association is maybe difficulties, which pose challenges.

Each nation has its shortcomings. I don't classify them as a problem but rather as challenges.

Difficulties you face [in a multicultural team] are not a problem but a challenge. It is interesting, not annoying. It requires more effort, though I also learn more.

The necessity to possess a good command of common, functional language appeared to be the most demanding job requirement in MNCs and it was frequently mentioned as a barrier to working relationships with foreigners:

I would feel better if I could depict certain issues in Polish, since a foreign language always restricts your communication. For example, my friend who has been living in Germany for years says that she was more abrupt, laconic and brusque whilst speaking German - it is like a language could change her personality.

There is a problem with communication. Not every employee is fluent in English, our corporate language. Accents differ, as a result there are misunderstandings and impediments. Besides, there are differences how to communicate something to a German (...) or an Indian.

[Communication is] a challenge not a barrier, but the greatest difficulties are in this area, a language barrier occurs. There are also some stereotypes, e.g. that the French or the Chinese don't like to speak English.

The biggest barrier is still the language. (...) In meetings with clients and business partners, who don't speak English, direct communication is limited, they cannot forge a relationship. They have to rely on the Polish staff in every situation.

However, an aptitude to communicate fluently in the functional language, which was enhanced due to job requirements in the MNCs that imposed on their 
staff the requirement to speak the "corporate tongue", was appreciated by the majority of the interviewees suggesting that for some of them such a demand could be classified as a challenge rather than a barrier:

I am proud that I work in such an [multicultural] environment. My parents are proud too, because I work for this company and I have a perfect command of English.

[The benefit of intercultural interactions is] language - an opportunity to improve it.

Working with foreigners lets you develop your language skills.

There are plenty of benefits (...) an occasion for working in another language, so we boost our linguistic competence.

The most obvious job demand was the need to manage the difference of attitudes, perspectives, views, habits, etc.:

[The first association is] the difference of approaches and perspectives, varied experiences and views.

[The quality of cooperation with foreigners depends on] reciprocal awareness and recognition of cultural differences.

[The problem is] management style, people have different mindsets.

I like diversity and learning. I am fond of working with foreigners. (...)

There are difficulties. You have to bear in mind that others may think and behave in a different way, since they have been raised in various cultures. (...) You need a wider imagination.

Such diversity was seen as a consequence of both cultural and personality differences:

Nationality is a matter of importance because it is a difference when you work with a German or a French. (...) There are cultural problems - a lack of understanding of Polish mentality or culture.

At the first encounter with other nations, until I learn how they react or behave in a certain situation, problems always show up. For instance, Germans prefer when their work is formalized. They will likely miss a meeting if the invitation to it with an agenda were not inserted into their Outlook.

[Nationality] has an impact [on cooperation], yet it basically depends on what a person is like.

[Communication efficiency] is determined by personality, it doesn't depend on nationality. A decisive factor is the level of language proficiency. Then communication is faster and more accurate.

Functioning in the multicultural environments of the MNCs and consequently facing differences required from the individuals ability to adjust and being flexible:

[My first associations are] challenge, adjustment, flexibility.

Working with foreigners means for me that some actions should be done
INTERCULTURAL

INTERACTIONS AT MULTINATIONAL

Małgorzata Rozkwitalska

Beata A. Basińska

Michał Chmielecki Sylwia Przytuła Łukasz Sułkowski 
INTERCULTURAL INTERACTIONS AT MULTINATIONAL

Małgorzata Rozkwitalska Beata A. Basińska Michał Chmielecki Sylwia Przytuła Lukasz Sułkowski in "another" way, interpreted according to or adapted to foreigners' needs, knowledge or their level of perception.

If both sides are open, you may try to compromise. If not, you should endeavor to adjust to the foreigner's culture, at the same time, not to lose your identity.

There are cultures for instance that like to do things slowly or fast, I have to give them a proper task.

Other job demands that emerged in the course of the interviews, which were typical of the work context in MNCs that operate on a global scale, included working in time zones and virtual teams that might also pose challenges or barriers to social integration of a diverse staff due to, for example, a lack of face to face communication:

You should take time zones into consideration and be flexible.

Additionally, [communication] would be easier if everyone worked in the same time zone.

The difficulty is due to distance working, so you don't have an actual reception of the other party but only an idea about him/her. (...) I wish I had more direct contacts, but can my company afford this? Is it a priority?

The main issues are communication, time zones and virtual teams, as a result a lack of face to face contact.

The MNCs' work context appeared to be highly demanding and competitive, in view of the study's participants' remarks, yet in return it also offered resources to facilitate the tasks actualization and interpersonal rapports, rarely available in other types of organizations, such as language and cross-cultural trainings, communication technology for dispersed teams, knowledge of databases, special initiatives, relocation and other amenities:

There are language courses available, not only in English. (...) My company provides effective tools for working in dispersed teams. There are business trips to meet with your team in one place and you are encouraged to the meetings. There are the company's on-line documents about countries (e.g. currency, transportation, basic information) and subsidiaries in these states (addresses, access routes, etc.).

[The benefit is] the access to the newest technology and a proven methodology of project management.

[My company prepares for intercultural interactions by] panel discussions, sending on foreign assignments, diversity days.

Hiring people with experience, a special system of "buddies", who take care of new people. The global village initiative thanks to which we get commuters together. [There are] sometimes flags on the desks and then people approach me and ask a few questions. 
Nonetheless, the number of, accessibility or quality of the resources essential for further smooth intercultural interactions might be insufficient, consequently producing barriers or hindrances to mutual relationships:

I think it would be recommended to prepare the leaders more for a multicultural environment. The leaders should give others the example. So maybe an additional training for them?

[The company could offer] more teambuilding events.

[The barriers are] (...) the unreliable video-conference technology (...).

[To improve the intercultural interactions my company could provide] access to the knowledge base where I could learn what nationalities work for the company. Some people would definitely feel more secure.

\subsection{Outcomes of intercultural demands}

It was salient in the participants' utterances that they often referred to the MNCs' work context as fulfilling their various personal needs. The need for development was the most significant one in terms of frequency of the informants' indications as well as considering its prominence for the respondents and their companies:

You gain personal development due to the contact with foreigners and a cultural exchange.

This job and contacts [with foreigners] compel you to self-development.

The biggest benefit of the intercultural interactions is your personal development (you watch others, cultures... it influences the decisions that you make later).

[Cooperation with foreigners means] language improvement, knowing work and life in the other places. Overseas assignments develop [people]. You may know different work methods, standards, meet new people.

It occurred evident in the course of the interviews that working in the unique workplaces of the MNCs made the individuals face challenges or barriers, contributing to their perspective broadening, knowledge sharing, and consequently enhanced learning with the result that their need for growth was satisfied:

Such contacts always teach you something and bring something. If they are with a foreigner, then you very often learn another country's culture and it is somewhat enrichment. Contacts with other states broaden your horizons. (...) The contacts with foreigners let you observe how they work and you learn.

We perceive the world in a different way due to multiculturalism. I feel a citizen of Europe. I don't have problems with assimilation.

[Working with foreigners means] new chances, new perspectives, new contacts. (...) It is great to travel, to get to know other cultures. You learn a lot.
INTERCULTURAL

INTERACTIONS AT MULTINATIONAL

Małgorzata Rozkwitalska

Beata A. Basińska

Michał Chmielecki Sylwia Przytuła Łukasz Sułkowski 
INTERCULTURAL INTERACTIONS AT MULTINATIONAL

Małgorzata Rozkwitalska Beata A. Basińska Michał Chmielecki Sylwia Przytuła Lukasz Sułkowski
You have a wider worldview, (...) you increase your knowledge. (...) We mutually learn while working with foreigners.

Such a demanding work environment activated the participants' and organizational creativity and innovation and simultaneously induced their adaptability and resilience:

You see different concepts and overcome rigid solutions, methods.

If tasks require creativity, it is better to have a diverse team.

You need to adjust your communication style to your interlocutor. If he/ she isn't fluent enough, you should use simple vocabulary.

We're able to do more, we're flexible.

The analysis of the data reveals that in multicultural environments of MNCs individuals might witness different emotional states, both positive and negative ones. The subsequent emotions were mentioned by the informants, namely curiosity, excitation, enthusiasm, pleasure, surprise, joy, frustration, anxiety, stress, impatience, homesickness:

We work as an international team. It is pleasant and great because we learn a lot from each other. (...) Individual efforts add and you don't feel alone.

At the beginning, you don't like it [i.e. a foreign working style], it's frustrating, but afterwards you start to appreciate it.

This job isn't stress-free. Yet it drives my energy, the continuous challenges you meet. I like that.

[My first association concerning intercultural interactions is] anxiety whether we will establish a proper contact, come to an understanding. It is also curiosity - different cultures, different worldviews.

Yet the positive emotions prevailed in the informants' remarks. Some of the research participants also felt satisfaction:

Such contacts give a lot of satisfaction, though there is anxiety at the beginning whether we'll understand each other.

[The benefits are] job satisfaction, a chance of development. I'm glad to work in a multicultural environment.

My face smiles - this is a diverse and energetic group of people. You want to work for them and to do various stuff. They come up with ideas on what to do.

[Working with foreigners is] fun. (...) I enjoy interacting with different people, that's my strongest skill.

\subsection{Personal and acquired resources}

Since working in multicultural settings of MNCs may be perceived as either barriers or challenges, individuals who are faced with such a demanding work environment should be equipped with unique personal resources. Hence, 
the research participants were asked what, in their opinion, determines the prevalence of the positives over the negatives while working with foreigners. Generally, the interviewees referred to the following: personality traits (i.e. openness, tolerance and looking for adventures), a positive attitude, acquired skills and experience.

As far as personality is concerned, openness was the most significant feature that, in view of the informants' remarks, determined their success in intercultural interactions:

Not everyone can find himself in such cooperation. You need humility, tact, openness, tolerance and to maintain a measure of detachment. You shouldn't prejudge. You have to be flexible.

[Success depends on] an individual's personality. No matter if you're a German or a Japanese. If he/she isn't open and doesn't want to share knowledge and to help others, you shouldn't blame the whole nationality.

[A person] should be open minded, patient and creative.

[The quality of cooperation] pivots on being open to listen to each other and understand geographical, political and cultural differences.

Open people are likely to be more effective in managing work stressors as well as more willing to interact with those from other cultures, presenting more cultural flexibility. Openness may therefore facilitate an individual's adjustment to the unique work demands in MNCs and boosts his/her resilience. With regard to the research, personality and attitudes also occurred in terms of personality developments, i.e. openness and tolerance:

Work brings people closer, especially work abroad, when you have direct contact, talk about habits etc. It increases your curiosity, and then respect for the other culture, history.

A contact [with a foreigner] lets you see the person in a different light, to challenge the stereotypes.

The presence of expatriates has a positive impact on the relationships with other foreigners, e.g. you may confront the stereotypes or change your attitude.

This job teaches you tolerance, more patience and humbleness.

The study showed that people working in multicultural environments may look for a variety and adventure:

Contacts with foreigners don't bother me, it's an element of curiosity, pros and cons.

For me it's a great color - curiosity to meet others, ability to learn and develop my worldview.

I wouldn't like to change that. It's more interesting [to work in multicultural teams].

[The benefit is] amazing friendships all over the world. 
INTERCULTURAL INTERACTIONS AT MULTINATIONAL

Małgorzata Rozkwitalska Beata A. Basińska Michał Chmielecki Sylwia Przytuła Lukasz Sułkowski
A positive attitude was another factor frequently mentioned by the participants of the study as a determinant of smooth relationships with foreigners. Additionally, not yielding to stereotypes, persevering toward the goals and motivation were recognized by them as symptoms of a positive approach to the representatives of different cultures:

[Success is determined by] your personal attitude toward others. Nationality is of some importance, yet I'd rather say that knowledge of other cultures is more important.

It is a person's attitude that needs to be oriented toward the benefits and pluses rather than the negatives, mistakes and weaknesses of the alien staff.

You need knowledge about a given culture. If you don't have it, you should at least have cognitive motivation to acquire the knowledge and to get rid of the stereotypes.

[Success depends on] mutual commitment. You need to communicate your goals clearly and then to strive for them. You have to be consistent and to doggedly pursue the goals of cooperation.

Since language and cultural diversity was perceived by the informants as specific features of the work context in MNCs, being successful in addressing these difficult challenges required, in their opinion, certain earlier acquired abilities, specifically speaking foreign languages or (less frequently mentioned) having social and technical skills:

If you just speak the same language, the rest is manageable. If you speak the same language, you will meet the needs of other people.

An expat manager needs to be able to listen and to have well-developed emotional intelligence, (...) to learn the local language.

Sensitivity, but it's not a skill you work out within a few days. Soft skills are essential. (...) We cannot start from scratch, there must already be some skills. (...) I prefer soft skills to analytical skills.

You have to be task-oriented and professional while handling your duties, be conscientious and meet deadlines.

It is also worth emphasizing with regard to the overall collected data that a person's belief that he/she demonstrates a sufficient level of the aforementioned skills and is capable to mobilize required motivation, resources and course of actions are enabling factors in intercultural interactions, as some of the interviewees commented:

In the beginning there was a panic. What will happen? Can I do this? And I did. Where there's will there's a way. (...) What doesn't kill me makes me stronger.

If someone wants to see the negatives, they will see them. Certainly, there 
are problems (...). If there is a problem, you have to solve it, this way or another.

You need to have confidence in your competences.

In the beginning, language can be a barrier, yet it's up to us if we surmount

it. (...) It depends on people whether they want or don't want to overcome problems.

Finally, both being active, as reflected for example in acquiring cross-cultural knowledge, looking for solutions or establishing direct contacts, as well as having international experience were considered by the interviewees as essential conditions for building proper rapports with foreigners:

It is good if an expat wants to know more about the host country, prepares for his/her foreign assignment, reads guidebooks.

A person should be open, eager to learn and have cognitive curiosity to check cultural profiles and read about other cultures.

[What is needed for intercultural interactions?] Speaking languages, openness toward otherness and previous experience in working with foreigners.

Cross-cultural experience is crucial for that job. You need to be positive.

\section{Discussions}

\subsection{Summary of the results}

The aim of this study was to examine social interactions in multicultural environments of MNCs and to propose a model of intercultural social interactions in MNCs' specific context (see Figure 1). The theoretical framework for this model is described in detail in the next part of the paper.

The study revealed that the respondents portrayed the specific job characteristics in MNCs either as challenges or hindrances. These job characteristics affected their social interaction at work. The respondents also emphasized the importance of job resources that facilitate dealing with job demands. Working in multicultural environments led to the following outcomes: satisfaction of the need for one's development due to learning, more positive than negative emotions and job satisfaction. With regard to the outcomes for an organization, creativity and innovation were emphasized. The previously acquired individual resources, namely international experience, practical linguistic skills as well as social and technical skills appeared necessary in shaping proper relationships with foreigners. The informants also referred to personality and a positive attitude as factors that may affect intercultural interactions. 


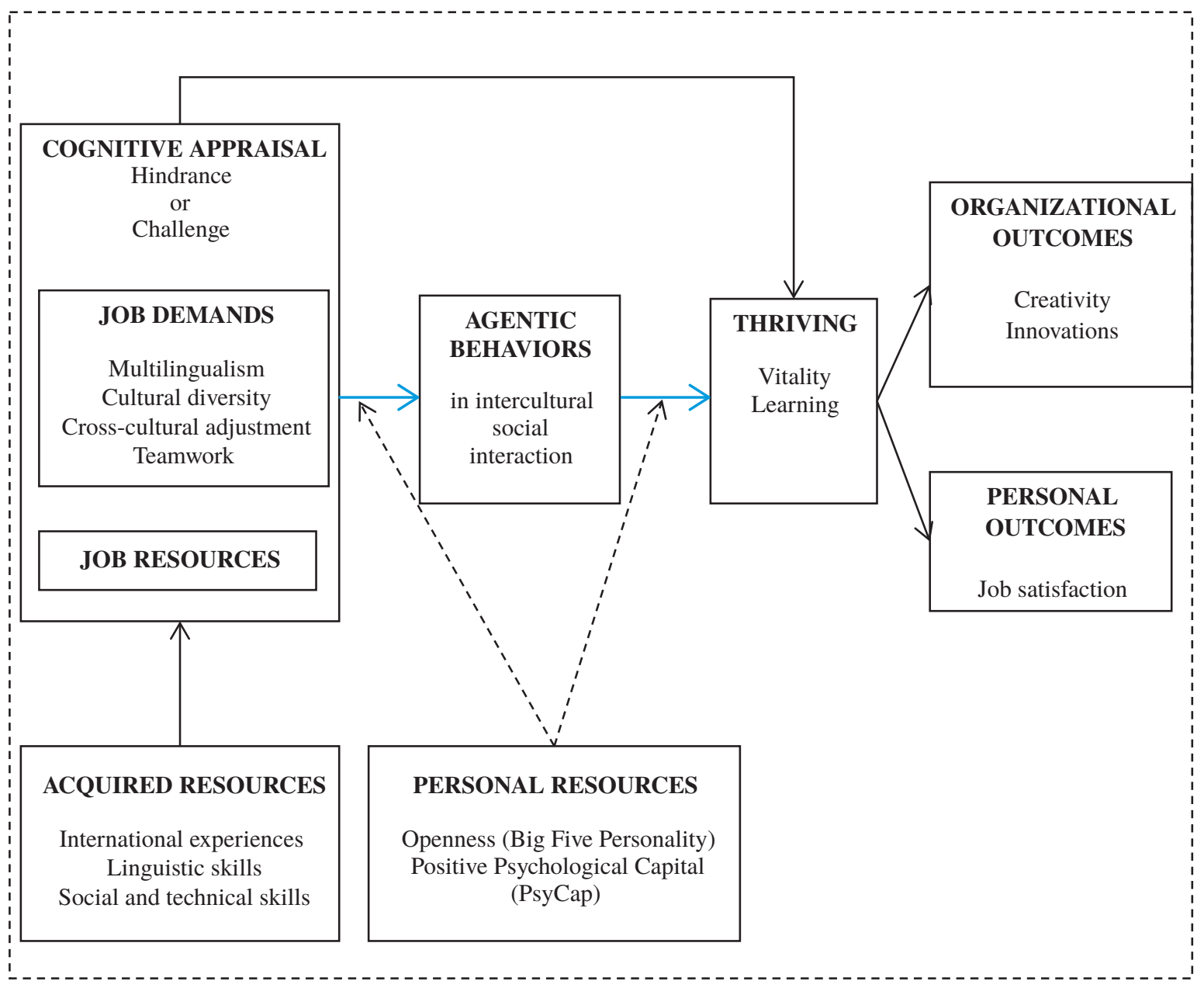

\section{Figure 1.}

Model of intercultural interaction in MNCs

Source:

Job demands: organizational context (JDR theory, Bakker and Demerouti, 2014); Cognitive appraisal: challenge or hindrance (transactional stress theory, Lazarus, 1991a; Cavanaugh et al., 2000); Agentic behaviors in social interactions (social learning theory, Bandura, 2001); Thriving (Spreitzer et al., 2005); Acquired resources: experience and skills; Personal resources: as a moderator in job demands - agentic behaviors and thriving (PsyCap, Luthans, Avolio, et al., 2007). Dotted line - moderation. Blue line - indirect relation. 
4.2. Cognitive appraisal of job characteristic in MNCs

The respondents while talking about specific job characteristics in multicultural environments such as multilingualism, cultural diversity and cross-cultural adjustment used the statement "a challenge" the most often. Moreover, they stressed the distinction between job characteristics as challenges and barriers. This may be due to the fact that the respondents evaluated the meaning and significance of the specific job demands. This approach is close to the cognitive appraisal, the key term used in the transactional stress theory (Lazarus and Folkman, 1984; Lazarus, 1991a) in general settings. In this theory, cognitive primary appraisal is considered to determine whether a specific situation is perceived as a challenge or a hindrance (i.e. threat). The distinctions are also clearly recognized in the challenge-hindrance occupational model (Cavanaugh et al., 2000). Challenge stressors require personal effort and induce strain, yet employees anticipate that they have necessary skills to deal with them. Challenge stressors are positively related to work performance, can improve work outcomes and have rewarded consequences for their employees (LePine et al., 2005). In contrast, hindrance stressors are considered to produce an adverse effect because individuals do not have a sufficient ability to deal with the barriers. Hindrance stressors impede the achievement of the occupational goals and they are negatively related to work outcomes. Moreover, hindrances limit personal development while challenges facilitate it (Webster et al., 2010).

It is worth noticing that the challenge-hindrance occupational model has some shortcomings (Edwards et al., 2014). The most important one is the assumption that each employee assesses specific job characteristics in the same manner. The transactional stress theory provides another explanation. Here a cognitive appraisal of job characteristics as a challenge or hindrance may depend on the personality traits, personal resources or early personal experience of employees (Lazarus, 1991b). The authors' empirical findings can be therefore further referred to these antecedents of cognitive appraisal.

\subsection{Personal resources as moderators of intercultural interaction}

Numerous of the interviewees in the research described themselves as open, curious and tolerant. They derived pleasure from cultural diversity that they met in the multicultural work environment. These personal characteristics are closely related to openness, the trait in Big Five theory of personality (McCrae and Costa, 1997). Openness to experience highlights characteristics like intellectual curiosity, non-conforming thinking, being imaginative and creative. The previous research also confirmed that open people utilize effective and creative solutions to manage work stressors" (You et al., 2015), can be more willing to interact cross-culturally and exhibit more cultural flexibility (Caligiuri and Tarique, 2012). It is possible that individuals working in multicultural environments are more open and this
INTERCULTURAL

INTERACTIONS AT MULTINATIONAL

Małgorzata Rozkwitalska Beata A. Basińska

Michał Chmielecki Sylwia Przytuła Łukasz Sułkowski 
INTERCULTURAL INTERACTIONS AT MULTINATIONAL

Małgorzata Rozkwitalska Beata A. Basińska Michał Chmielecki Sylwia Przytuła Lukasz Sułkowski disposition facilitates them to take a job and adjust to specific conditions. However, a complementary explanation may be offered by the Positive Psychological Capital approach (Luthans and Youssef, 2007), which draws from Positive Organizational Behavior (Luthans and Youssef, 2007) and Positive Organizational Scholarship (Cameron et al., 2003).

Positive Psychological Capital (PsyCap) is a personal resource of self-efficacy, hope, optimism and resilience. The concept enables a better understanding of the perception of stress and how individuals cope with it. In contrast to personality traits, PsyCap is an individual's positive state of development. All the four components of PsyCap have a synergistic effect on positive organizational behaviors (Avey et al., 2009). Specifically, self-efficacy is described as a belief to take on and put in necessary effort to succeed in a challenging task. Further, optimism facilitates a positive attribution about current and future success. Additionally, hope allows for a persistent pursuit of a goal and renewing the paths leading to the goal. Finally, resilience helps people to be flexible when difficulties arise (Luthans et al., 2007; Luthans et al., 2010). With regard to the authors' study, the respondents were convinced that their linguistic ability and technical skills helped them to achieve the occupational goals despite some barriers and hindrances they encountered (self-efficacy). They also indicated that many job demands were hard and difficult at the first moment, but willingness to learn (i.e. the interviewees' optimism) and motivation for looking for different paths to achieve the goals (i.e. the respondents' hope) could lead them to success. Moreover, the research participants' flexibility and tolerance, particularly in view of cultural stereotypes, fostered the appraisal of specific demands more as a challenge than hindrance.

\subsection{Bandura's agentic perspective on social interactions}

Personal resources and ascribed cognitive appraisal of job demands reflect being active at work that is rich in intercultural social interactions. The agentic perspective of the social cognitive theory (Bandura, 2001) proposes a deeper understanding of this process. In this theory personal agency operates within a broad network of social interactions. The agentic transactions engage individuals as both producers and products of social systems. Social interactions in MNCs due to cultural diversity are more demanding than common interpersonal interactions. In the authors' study the respondents indicated that being active and motivated to learn made them agents in interpersonal interactions. Furthermore, the participants working in the MNCs emphasized that the job resources offered by their companies such as language and cross-cultural trainings, communication enabling technology for dispersed teams, and other amenities and rewards, facilitated them to be active and agentic. These job resources are helpful in achieving work goals, reduce cost of job demands as well as stimulate one's personal growth, learning 
and development (Bakker and Demerouti, 2014). Moreover, accessibility of these resources strengthens collective agency and ability to master experiences, modeling, social persuasion and activity (Bandura, 2000).

\subsection{Thriving in intercultural social interactions}

Thriving offers a new insight into being agents in social interactions at work. It can further help to explain the empirical findings.

Thriving at work can be seen as a conscious psychological state composed of a sense of vitality and learning (Spreitzer et al., 2005). The learning component of thriving contributes to an individual's sense of competence and efficacy whereas vitality is perceived as positive energy (Quinn, 2009). Thriving employees seek pleasurable experience and want to realize their potential (Spreitzer et al., 2005; Paterson et al., 2014). According to this concept, work and the social context interplay and consequently promote positive functioning of employees. Thriving at work is a self-adaptive process. It fosters an individual's growth (Paterson et al., 2014). Thriving employees shape their work context to enhance their growth (Spreitzer et al., 2005). Social interactions among people, especially working in MNCs and facing cultural diversity, show what needs to be improved and how it can be done (Carmeli et al., 2009). This is the essence of organizational learning and it only takes place in social interactions, additionally invigorating vitality (Spreitzer et al., 2005; Quinn, 2009).

In the authors' study the respondents argued that many challenges resulted from the MNCs' work environments were a natural source of learning and development of their competency. They also indicated that work and intercultural social interactions generated positive feelings and states. It is worth emphasizing that thriving, which consists of joint experience of vitality and learning, enhances both individual outcomes such as job satisfaction and organizational ones such as creativity and innovation, which can be interrelated (Niu, 2014). Hence, thriving may result in organizational development and organizational knowledge building, increasing in the same time a company's competitive advantage on the global and highly competitive market.

\section{Conclusions}

To sum up the discourse of the paper, working in multicultural environments of MNCs may generate specific job demands which can be evaluated as challenges or hindrances. MNCs support their employees by providing occupational resources that facilitate the process of dealing with the specific job demands. Additionally, some personal resources, particularly positive psychological capital, encourage agentic behaviors in intercultural social interactions. The acquired skills and international experience can also help to adapt to multicultural work environments of MNCs. The effect of agentic behavior in these interactions is thriving, which
INTERCULTURAL

INTERACTIONS AT MULTINATIONAL

Małgorzata Rozkwitalska Beata A. Basińska Michał Chmielecki Sylwia Przytuła Łukasz Sułkowski 
INTERCULTURAL INTERACTIONS AT MULTINATIONAL

Małgorzata Rozkwitalska Beata A. Basińska Michał Chmielecki Sylwia Przytuła Łukasz Sułkowski increases an employee's learning, satisfy the need for development, expands vitality and positive emotional states as well as benefits the very organization by means of creativity and innovations. Thus, agentic behaviors can be mediators between job demands and thriving, while the concept of thriving can serve as a mechanism of relations between interactions undertaken due to MNCs' specific job demands and their personal and organizational outcomes.

\subsection{Contributions, practical and social implications}

The proposed model focuses on social interactions in MNCs' multicultural context. Thus, the paper contributes mainly to the literature on intercultural management and cultural diversity and helps to explain some irregularities in the prior studies (e.g. Mannix and Neale, 2005; Stahl et al., 2010) that have been observed concerning the outcomes of interactions among culturally diverse individuals. First and foremost, it emphasizes that those outcomes depend on how individuals assess their job demands in MNCs. Availability of job resources can be another factor that shapes intercultural social interactions and their effects in unique environments of MNCs. The authors also stress the role of personal resources, such as personality traits and a positive attitude, and acquired resources, e.g. international experience, which were partially and usually separately included in the concepts of cross-cultural competence, cultural intelligence and intercultural effectiveness (e.g. Fisher and Härtel, 2006; Johnson et al., 2006; Ang et al., 2007; Spitzberg and Changnon, 2009; Panggabean et al., 2013). The proposed model also refers to PsyCap in cross-cultural settings, which has recently attracted the attention of researchers (Dollwet and Reichard, 2014; Reichard et al., 2014). Therefore, the authors' emergent theory of intercultural social interactions appears to be more holistic and integrative than the previous concepts because it explains the outcomes of those interactions, their antecedents and moderators.

Since the empirical findings have been interpreted with regard to psychological and sociological theories and the Positive Organizational Scholarship lens, the emergent theory of intercultural interactions that is proposed in the paper moves beyond the old paradigms and delves into the positive phenomena responding to the calls of Shore et al., (2009), Stahl et al., (2010) and (Stahl and Tung, 2014). The study satisfies the need for positive cross-cultural scholarship and augments relatively limited number of qualitative research on outcomes of intercultural interactions.

The authors' model can be helpful in advising managers in MNCs what is needed to enable diverse individuals to thrive. Since the workplace in MNCs is abundant in learning opportunities, managers of MNCs should hire employees who exhibit needs for growth and development to boost thriving in their organizations. Additionally, such managers should search for employees 
with experience of multicultural settings and a significant capacity of PsyCap, thanks to which they are likely to benefit more from intercultural interactions as confirmed in the research of Dollwet and Reichard (2014) and Reichard et al., (2014). More concern should be put on training the employees' language skills since it may build their self-efficacy in intercultural interactions. Further, to improve intercultural interactions, managers in MNCs should both enhance the employees' positive attitudes towards their job as well as foster positive emotions at work. For instance, emotion management can enhance positive emotions since it has potential for conflict successful channeling in diverse settings (Ayoko and Konrad, 2012). Managers in MNCs should also display more concern for their employees' affective states (Quinn, 2009) in intercultural interactions because then they improve their people's opportunities for learning and development (Porath et al., 2012).

Today's societies are becoming more and more multicultural, which raises the need for boosting society members' awareness of the possible positive outcomes of cultural diversity at work, especially that exchanging views and experience among multicultural staff furthers their thriving and consequently well-being (Porath et al., 2012), contributing to the overall health of society. The authors' research provides evidence that the multicultural work context of MNCs activates potential, which is inclusive of thriving.

\subsection{Limitations and future research}

The grounded theory approach has been used in the paper to create a model of intercultural social interactions in MNCs. The methodology applied to the research does not allow for generalization beyond the substantive study (Kempster and Parry, 2011). Hence, directions for future research incorporate a further quantitative empirical verification of the proposed model, particularly in examining the role of personal resources as moderators and the indirect role of agentic behavior between the antecedents of intercultural interactions and their outcomes in MNCs.

Since the authors' theory is grounded in a specific setting of Poland, where the data was collected, future qualitative and quantitative research should encompass more countries to compare whether multicultural environments' characteristics in MNCs differ among state contexts. For instance, it would be interesting to compare the results among MNCs that operate in more ethnically and racially diverse societies such as the Unites States and less diverse ones, e.g. Poland, or to analyze a multilingualism challenge in MNCs that operate in English speaking and non-English speaking countries. Thus, other researchers should verify the grounded theory in other contexts "to extrapolate whether a theory from one context is generalizable to another" (Kempster and Parry, 2011).
INTERCULTURAL INTERACTIONS AT MULTINATIONAL

Małgorzata Rozkwitalska Beata A. Basińska Michał Chmielecki Sylwia Przytuła Łukasz Sułkowski 
INTERCULTURAL INTERACTIONS AT MULTINATIONAL

Małgorzata Rozkwitalska Beata A. Basińska Michał Chmielecki Sylwia Przytuła Lukasz Sułkowski

\section{Acknowledgements}

The authors report the empirical findings from the first stage of the project financed by National Science Centre in Poland (the research grant no. DEC-2013/09/B/HS4/00498, entitled "Crosscultural interactions in foreign subsidiaries of multinational corporations - traditional and Positive Organizational Scholarship approaches").

\section{References}

Ang, S., Van Dyne, L., Koh, C., Ng, K. Y., Templer, K. J., Tay, C., Chandrasekar, N. A. (2007), "Cultural intelligence: Its measurement and effects on cultural judgment and decision making, cultural adaptation and task performance", Management and Organization Review, Vol. 3 No. 3, pp. 335-371. DOI: http://dx.doi.org/10.1111/j. 1740-8784.2007.00082.x

Avey, J. B., Luthans, F., Jensen, S. M. (2009), "Psychological capital: A positive resource for combating employee stress and turnover", Human Resource Management, Vol. 48 No. 5, pp. 677-693. DOI: http://dx.doi.org/10.1002/hrm.20294

Ayoko, O. B., Konrad, A. M. (2012), 'Leaders' transformational, conflict, and emotion management behaviors in culturally diverse workgroups", Equality, Diversity and Inclusion: An International Journal, Vol. 31 No. 8, pp. 694-724.

Bakker, A., Demerouti, E. (2014), "Job demands-resources theory", in: Chen, P. Y., Cooper, C. L. (Eds.), Work and Wellbeing: Wellbeing: A complete reference guide, Wiley-Blackwell, Chichester, pp. 37-64.

Bandura, A. (2000), "Exercise of human agency through collective efficacy", Current Drections in Psychological Science, Vol. 9 No. 3, pp. 75-78. DOI: http://dx.doi. org/10.1111/1467-8721.00064

Bandura, A. (2001), "Social cognitive theory: An agentic perspective", Annual Review of Psychology, Vol. 52 No. 1, pp. 1-26. DOI: http://dx.doi.org/10.1146/annurev. psych.52.1.1

Brien, A., Smallman, C. (2011), “The respected manager... the organisational social capital developer", International Journal of Hospitality Management, Vol. 30 No. 3, pp. 639-647.

Caligiuri, P., Tarique, I. (2012), "Dynamic cross-cultural competencies and global leadership effectiveness", Journal of World Business, Vol. 47 No. 4, pp. 612-622. DOI: http://dx.doi.org/10.1016/j.jwb.2012.01.014

Cameron, K. S., Dutton, J. E., Quinn, R. E. (2003), “An introduction to positive organizational scholarship", in: Cameron, K. S., Dutton, J. E., Quinn, R. E. (Eds.), Positive organizational scholarship, Berrett-Koehler, San Francisco, pp. 3-13.

Caprar, D. V. (2011), "Foreign locals: A cautionary tale on the culture of MNC local employees", Journal of International Business Studies, Nature Publishing Group, Vol. 42 No. 5, pp. 608-628. DOI: http://dx.doi.org/10.1057/jibs.2011.9

Carmeli, A., Brueller, D., Dutton, J. E. (2009), "Learning behaviours in the workplace: The role of high-quality interpersonal relationships and psychological safety", Systems Research and Behavioral Science, Vol. 98 No. November 2008, pp. 81-98. DOI: http://dx.doi.org/10.1002/sres.932 
Cavanaugh, M., Boswell, W., Roehling, M., Boudreau, J. (2000), “An empirical examination of self-reported work stress among US managers", Journal of Applied Psychology, Vol. 85 No. 1, pp. 65-74.

Cooper, D., Doucet, L., Pratt, M. (2007), “Understanding 'appropriateness' in multinational organizations”, Journal of Organizational Behavior, Vol. 28 No. 3, pp. 303-325.

Corbin, J., Strauss, A. L. (2008), Basics of Qualitative Research, Sage Publications, Thousand Oaks.

Darawong, C., Igel, B. (2012), "Acculturation of local new product development team members in MNC subsidiaries in Thailand", Asia Pacific Journal of Marketing and Logistics, Vol. 24 No. 3, pp. 351-371. DOI: http://dx.doi.org/10.1108/13555851211237867

Dearnley, C. (2005), "A reflection on the use of semi-structured interviews", Nurse researcher, Vol. 13 No. 1, pp. 19-28. DOI: http://dx.doi.org/10.7748/nr2005.07.13. 1.19.c5997

Dollwet, M., Reichard, R. (2014), “Assessing cross-cultural skills: Validation of a new measure of cross-cultural psychological capital", International Journal of Human Resource Management, Vol. 25 No. 12, pp. 1669-1696. DOI: http://dx.doi.org/10.10 80/09585192.2013.845239

Edwards, B. D., Franco-Watkins, A. M., Cullen, K. L., Howell, J. W., Acuff, R. E. (2014), "Unifying the challenge-hindrance and sociocognitive models of stress", International Journal of Stress Management, Vol. 21 No. 2, pp. 162-185. DOI: http://dx.doi. org/10.1037/a0034730

Fisher, G. B., Härtel, C. E. J. (2006), "Cross-cultural effectiveness of western expatriateThai client interactions: Lessons learned for IHRM research and theory", Cross Cultural Management: An International Journal, Vol. 12 No. 3, pp. 32-62.

Glaser, B. G., Strauss, A. L. (1999), The Discovery of Grounded Theory: Strategies for Qualitative Research, Aldine De Gruyter, Hawthorne.

Goulding, C. (1998), "Grounded theory: the missing methodology on the interpretivist agenda”, Qualitative Market Research: An International Journal, Vol. 1 No. 1, pp. 50-57. DOI: http://dx.doi.org/10.1108/13522759810197587

Graham, J. L. (2010), "Culture and human resources management”, in: Rugman, A. M. (Ed.), Oxford Handbook of International Business, Oxford University Press, New York, pp. 502-536.

Hassi, A., Storti, G., Azennoud, A. (2011), “Corporate trainers' credibility and cultural values: evidence from Canada and Morocco", Cross Cultural Management: An International Journal, Vol. 18 No. 4, pp. 499-519.

HRM spreads word to the world, (2012), "HRM spreads word to the world: When culture and country affect company", Human Resource Management International Digest, Vol. 20 No. 3, pp. 18-21.

Johnson, J. P., Lenartowicz, T., Apud, S. (2006), "Cross-cultural competence in international business: toward a definition and a model", Journal of International Business Studies, Vol. 37 No. 4, pp. 525-543. DOI: http://dx.doi.org/10.1057/pal grave.jibs. 8400205

Kempster, S., Parry, K. W. (2011), "Grounded theory and leadership research: A critical realist perspective", The Leadership Quarterly, Vol. 22 No. 1, pp. 106-120. DOI: http://dx.doi.org/10.1016/j.leaqua.2010.12.010
INTERCULTURAL INTERACTIONS AT MULTINATIONAL

Małgorzata Rozkwitalska Beata A. Basińska Michał Chmielecki Sylwia Przytuła Łukasz Sułkowski 
INTERCULTURAL INTERACTIONS AT MULTINATIONAL

Małgorzata Rozkwitalska Beata A. Basińska Michał Chmielecki Sylwia Przytuła Lukasz Sułkowski
Lauring, J. (2009), "Managing cultural diversity and the process of knowledge sharing: A case from Denmark", Scandinavian Journal of Management, Vol. 25 No. 4, pp. 385-394. DOI: http://dx.doi.org/10.1016/j.scaman.2009.09.002

Lauring, J., Klitmøller, A. (2014), "Corporate language-based communication avoidance in MNCs: A multi-sited ethnography approach", Journal of World Business, Vol. 50 No. 1, pp. 1-10. DOI: http://dx.doi.org/10.1016/j.jwb.2014.01.005

Lauring, J., Selmer, J. (2011), "Multicultural organizations: common language, knowledge sharing and performance", Personnel Review, Vol. 40 No. 3, pp. 324-343. DOI: http:// dx.doi.org/10.1108/00483481111118649

Lazarus, R. (1991a), “Cognition and motivation in emotion”, American psychologist, Vol. 46 No. 4, pp. 352-367.

Lazarus, R. (1991b), "Psychological stress in the workplace", Handbook on job stress: A special Issue of the Journal of Social Behaviour and Personality, Vol. 6, pp. 1-20.

Lazarus, R., Folkman, S. (1984), Stress, Appraisal, and Coping, Springer, New York.

LePine, J., Podsakoff, N., LePine, M. (2005), "A meta-analytic test of the challenge stressor-hindrance stressor framework: An explanation for inconsistent relationships among stressors and performance", Academy of Management Journal, Vol. 48 No. 5, pp. 764-775.

Loh, J., Min, I., Restubog, S. L. D., Gallois, C. (2009), "The nature of workplace boundaries between Australians and Singaporeans in multinational organizations: A qualitative inquiry", Cross Cultural Management: An International Journal, Vol. 16 No. 4, pp. 367-385.

Luthans, F., Avey, J., Avolio, B., Peterson, S. (2010), “The development and resulting performance impact of positive psychological capital", Human Resource Management Quarterly, Vol. 21 No. 1, pp. 41-67. DOI: http://dx.doi.org/10.1002/hrdq.20034

Luthans, F., Avolio, B. J., Avey, J. B., Norman, S. M. (2007), "Positive psychological capital: Measurement and relationship with performance and satisfaction", Personnel Psychology, Vol. 60 No. 3, pp. 541-572. DOI: http://dx.doi.org/10.1111/j.1744-6 570.2007.00083.x

Luthans, F., Youssef, C. M. (2007), "Emerging Positive Organizational Behavior", Journal of Management, Vol. 33 No. 3, pp. 321-349. DOI: http://dx.doi.org/10.11 77/0149206307300814

Luthans, F., Youssef, C. M., Avolio, B. J. (2007), Psychological Capital: Investing and developing positive organizational behavior, in: Nelson, J., Cooper, C. L. (Eds.), Positive Organizational Behavior, Thousand Oaks, pp. 9-24.

Mannix, E., Neale, M. A. (2005), "What differences make a difference?: The promise and reality of diverse teams in organizations", Psychological Science in the Public Interest, Vol. 6 No. 2, pp. 31-55. DOI: http://dx.doi.org/10.1111/j.1529-1006.2005.00022.x

Maxwell, J. A. (2005), Qualitative Research Design: An Interactive Approach, Sage Publications, Thousand Oaks.

McCrae, R. R., Costa, P. T. (1997), "Personality trait structure as a human universal", The American Psychologist, Vol. 52 No. 5, pp. 509-516. DOI: http://dx.doi. org/10.1037/0003-066X.52.5.509 
McMillan-Capehart, A. (2005), "A configurational framework for diversity: socialization and culture", Personnel Review, Vol. 34 No. 4, pp. 488-503. DOI: http://dx.doi. org/10.1108/00483480510599798

Molinsky, A. (2007), "Cross-cultural code-switching: the psychological challenges of adapting behavior in foreign cultural interactions", Academy of Management Review, Vol. 32 No. 2, pp. 622-640. DOI: http://dx.doi.org/10.5465/AMR.2007.24351878

Müller, C. V. (1998), "About differences and blind spots: A systemic view on an international, interdisciplinary research team", Journal of Managerial Psychology, Vol. 13 No. 3/4, pp. 259-270.

Niu, H. J. (2014), "Is innovation behavior congenital? Enhancing job satisfaction as a moderator", Personnel Review, Vol. 43 No. 2, pp. 288-302. DOI: http://dx.doi. org/10.1108/PR-12-2012-0200

Noorderhaven, N., Harzing, A. W. (2009), "Knowledge sharing and social interactions within MNCs", Journal of International Business Studies, Vol. 40 No. April, pp. 719-741.

Panggabean, H., Murniati, J., Tjitra, H. (2013), "Profiling intercultural competence of Indonesians in Asian workgroups", International Journal of Intercultural Relations, Vol. 37 No. 1, pp. 86-98. DOI: http://dx.doi.org/10.1016/j.ijintrel.2012.04.002

Paterson, T. A., Luthans, F., Jeung, W. (2014), “Thriving at work: Impact of psychological capital and supervisor support", Journal of Organizational Behavior, Vol. 35 No. 3, pp. 434-446. DOI: http://dx.doi.org/10.1002/job.1907

Pettigrew, T. F., Tropp, L. R. (2008), "How does intergroup contact reduce prejudice? Meta-analytic tests of three mediators", European Journal of Social Psychology, Vol. 38 No. 6, pp. 922-934. DOI: http://dx.doi.org/10.1002/ejsp.504

Porath, C., Spreitzer, G., Gibson, C., Garnett, F. G. (2012), "Thriving at work: Toward its measurement, construct validation, and theoretical refinement", Journal of Organizational Behavior, Vol. 275 No. May 2011, pp. 250-275. DOI: http://dx.doi. org/10.1002/job.756

Przytuła, S., Rozkwitalska, M., Chmielecki, M., Sułkowski, Ł., Basinska, B. A. (2014), "Cross-cultural interactions between expatriates and local managers in the light of Positive Organizational Behaviour", Social Sciences (Socialiniai mokslai), Vol. 4 No. 4, pp. 14-24.

Quinn, R. W. (2009), "Energizing others in work connections”, in: Dutton, J., Ragins, B. R. (Eds.), Exploring Positive Relationships at Work. Building a Theoretical and Research Foundation, Psychology Press, New York, London, pp. 73-90.

Randall, W. S., Mello, J. E. (2012), "Grounded theory: an inductive method for supply chain research", in: Flint, D. (Ed.), International Journal of Physical Distribution \& Logistics Management, Vol. 42 No. 8/9, pp. 863-880.

Reichard, R. J., Dollwet, M., Louw-Potgieter, J. (2014), “Development of cross-cultural psychological capital and Its relationship with cultural intelligence and ethnocentrism", Journal of Leadership and Organizational Studies, Vol. 21 No. 2, pp. 154-164. DOI: http://dx.doi.org/10.1177/1548051813515517

Roberge, M.É., van Dick, R. (2010), "Recognizing the benefits of diversity: When and how
INTERCULTURAL INTERACTIONS AT MULTINATIONAL

Małgorzata Rozkwitalska Beata A. Basińska Michał Chmielecki Sylwia Przytuła Łukasz Sułkowski 
INTERCULTURAL INTERACTIONS AT MULTINATIONAL

Małgorzata Rozkwitalska Beata A. Basińska Michał Chmielecki Sylwia Przytuła Lukasz Sułkowski does diversity increase group performance?", Human Resource Management Review, Vol. 20 No. 4, pp. 295-308. DOI: http://dx.doi.org/10.1016/j.hrmr.2009.09.002

Rozkwitalska, M., Chmielecki, M., Przytuła, S. (2014), "The positives of cross-cultural interactions in MNCs", Actual Problems of Economics, Vol. 57 No. 7, pp. 382-392.

Sánchez Bengoa, D., Ruediger Kaufmann, H., Vrontis, D. (2012), "A new organisational memory for cross-cultural knowledge management", Cross Cultural Management: An International Journal, Vol. 19 No. 3, pp. 336-351.

Shore, L. M., Chung-Herrera, B. G., Dean, M. A., Ehrhart, K. H., Jung, D. I., Randel, A. E., Singh, G. (2009), "Diversity in organizations: Where are we now and where are we going?", Human Resource Management Review, Vol. 19 No. 2, pp. 117-133. DOI: http://dx.doi.org/10.1016/j.hrmr.2008.10.004

Spitzberg, B. H., Changnon, G. (2009), "Conceptualizing Intercultural Competence”, in: Deardorff, D. K. (Ed.), The SAGE Handbook of Intercultural Competence, Sage Publications, pp. 2-52.

Spreitzer, G., Sutcliffe, K., Dutton, J., Sonenshein, S., Grant, A. M. (2005), “A socially embedded model of thriving at work", Organization Science, Vol. 16 No. 5, pp. 537-549. DOI: http://dx.doi.org/10.1287/orsc.1050.0153

Stahl, G. K., Mäkelä, K., Zander, L., Maznevski, M. L. (2010), “A look at the bright side of multicultural team diversity", Scandinavian Journal of Management, Vol. 26 No. 4, pp. 439-447. DOI: http://dx.doi.org/10.1016/j.scaman.2010.09.009

Stahl, G. K., Maznevski, M. L., Voigt, A., Jonsen, K. (2009), "Unraveling the effects of cultural diversity in teams: A meta-analysis of research on multicultural work groups", Journal of International Business Studies, Vol. 41 No. 4, pp. 690-709. DOI: http:// dx.doi.org/10.1057/jibs.2009.85

Stahl, G. K., Tung, R. L. (2014), "Towards a more balanced treatment of culture in international business studies: The need for positive cross-cultural scholarship", Journal of International Business Studies, Vol. 46 No. 4, pp. 1-24. DOI: http://dx.doi. org/10.1057/jibs.2014.68

Takeuchi, R., Chen, J. (2013), “The impact of international experiences for expatriates' cross-cultural adjustment: A theoretical review and a critique", Organizational Psychology Review, Vol. 3 No. 3, pp. 248-290.

Tanova, C., Nadiri, H. (2010), "The role of cultural context in direct communication", Baltic Journal of Management, Vol. 5 No. 2, pp. 185-196.

Webb, A., Wright, P. C. (1996), "The expatriate experience: implications for career success", Career Development International, Vol. 1 No. 5, pp. 38-44. DOI: http:// dx.doi.org/10.1108/13620439610130632

Webster, J., Beehr, T., Christiansen, N. (2010), "Toward a better understanding of the effects of hindrance and challenge stressors on work behavior", Journal of Vocational Behavior, Vol. 76 No. 1, pp. 68-77. DOI: http://dx.doi.org/10.1016/j. jvb.2009.06.012

White, D. W., Absher, R. K., Huggins, K. A. (2011), “The effects of hardiness and cultural distance on sociocultural adaptation in an expatriate sales manager population", Journal of Personal Selling and Sales Management, Vol. 31 No. 3, pp. 325-338. DOI: http://dx.doi.org/10.2753/PSS0885-3134310309 
You, X., Huang, J., Wang, Y., Bao, X. (2015), "Relationships between individual-level factors and burnout: A meta-analysis of Chinese participants", Personality and Individual Differences, Vol. 74, pp. 139-145. DOI: http://dx.doi.org/10.1016/j. paid.2014.09.048

Youssef, C. M., Luthans, F. (2012), "Positive global leadership", Journal of World Business, Vol. 47 No. 4, pp. 539-547. DOI: http://dx.doi.org/10.1016/j. jwb.2012.01.007
INTERCULTURAL INTERACTIONS AT MULTINATIONAL

Małgorzata Rozkwitalska Beata A. Basińska Michał Chmielecki Sylwia Przytuła Łukasz Sułkowski 
INTERCULTURAL INTERACTIONS AT MULTINATIONAL

Małgorzata Rozkwitalska Beata A. Basińska Michał Chmielecki Sylwia Przytuła Łukasz Sułkowski

\section{Appendix 1.}

The interviewees' particulars (number of interviewees and share)

\section{Appendix}

\begin{tabular}{|c|c|c|c|c|c|c|c|c|}
\hline $\begin{array}{l}\text { an interviewee's } \\
\text { particulars }\end{array}$ & Subsidiary & $\mathbf{A}$ & B & $\mathbf{C}$ & D & $\mathbf{E}$ & total & Percentage \\
\hline \multirow{5}{*}{ job position } & top level managers & 4 & 1 & 1 & 0 & 0 & 6 & 8.6 \\
\hline & middle level managers & 9 & 1 & 5 & 0 & 4 & 19 & 27.1 \\
\hline & first-line managers & 3 & 4 & 6 & 1 & 5 & 19 & 27.1 \\
\hline & Specialists & 4 & 12 & 0 & 7 & 3 & 26 & 37.1 \\
\hline & Total & 20 & 18 & 12 & 8 & 12 & 70 & 100.0 \\
\hline \multirow{3}{*}{ Sex } & Men & 14 & 9 & 5 & 2 & 5 & 35 & 50.0 \\
\hline & Women & 6 & 9 & 7 & 6 & 7 & 35 & 50.0 \\
\hline & Total & 20 & 18 & 12 & 8 & 12 & 70 & 100 \\
\hline \multirow{6}{*}{ years of services } & less than 5 years & 7 & 14 & 0 & 6 & 8 & 35 & 50.0 \\
\hline & more than 5 less than 10 years & 6 & 3 & 7 & 0 & 0 & 16 & 22.9 \\
\hline & more than 10 less than 15 years & 3 & 1 & 4 & 2 & 3 & 13 & 18.6 \\
\hline & more than 15 less than 20 years & 3 & 0 & 1 & 0 & 1 & 5 & 7.1 \\
\hline & more than 20 years & 1 & 0 & 0 & 0 & 0 & 1 & 1.4 \\
\hline & Total & 20 & 18 & 12 & 8 & 12 & 70 & 100 \\
\hline \multirow{6}{*}{ Age } & 20-29 years old & 5 & 10 & 9 & 4 & 1 & 29 & 41.4 \\
\hline & 30-39 years old & 4 & 6 & 2 & 3 & 8 & 23 & 32.9 \\
\hline & $40-49$ years old & 4 & 1 & 1 & 1 & 3 & 10 & 14.3 \\
\hline & 50-59 years old & 6 & 1 & 0 & 0 & 0 & 7 & 10.0 \\
\hline & more than 60 years old & 1 & 0 & 0 & 0 & 0 & 1 & 1.4 \\
\hline & total & 20 & 18 & 12 & 8 & 12 & 70 & 100.0 \\
\hline \multirow{11}{*}{$\begin{array}{l}\text { organizational } \\
\text { unit }\end{array}$} & board of directors & 5 & 1 & 1 & 0 & 0 & 7 & 10.0 \\
\hline & operations & 7 & 0 & 8 & 6 & 1 & 22 & 31.4 \\
\hline & finance & 0 & 4 & 0 & 0 & 1 & 5 & 7.1 \\
\hline & $\begin{array}{l}\text { quality, health \& safety, } \\
\text { environmental protection }\end{array}$ & 2 & 1 & 0 & 0 & 2 & 5 & 7.1 \\
\hline & purchase and logistics & 2 & 0 & 0 & 0 & 1 & 3 & 4.3 \\
\hline & HR/administration & 1 & 5 & 0 & 0 & 3 & 9 & 12.9 \\
\hline & IT/technical support & 1 & 1 & 2 & 1 & 3 & 8 & 11.4 \\
\hline & accounting & 1 & 0 & 0 & 1 & 1 & 3 & 4.3 \\
\hline & $\mathrm{R}+\mathrm{D}$ & 0 & 5 & 0 & 0 & 0 & 5 & 7.1 \\
\hline & marketing/sale & 1 & 1 & 1 & 0 & 0 & 3 & 4.3 \\
\hline & total & 20 & 18 & 12 & 8 & 12 & 70 & 100 \\
\hline
\end{tabular}




\begin{tabular}{lllllllll}
\hline $\begin{array}{l}\text { an interviewee's } \\
\text { particulars }\end{array}$ & Subsidiary & A & $\mathbf{B}$ & $\mathbf{C}$ & $\mathbf{D}$ & $\mathbf{E}$ & total & Percentage \\
\hline & previous work for a MNC & 6 & 12 & 8 & 7 & 8 & 41 & 58.5 \\
\cline { 2 - 9 } & working abroad & 14 & 13 & 12 & 5 & 8 & 52 & 74.3 \\
\cline { 2 - 9 } & living abroad & 14 & 13 & 11 & 5 & 10 & 53 & 75.7 \\
\cline { 2 - 9 } $\begin{array}{l}\text { international } \\
\text { experience }\end{array}$ & studying abroad & 3 & 6 & 4 & 3 & 5 & 21 & 30.0 \\
\cline { 2 - 9 } & private trip abroad & 16 & 18 & 12 & 8 & 11 & 65 & 92.9 \\
\cline { 2 - 8 } & business trip abroad & 12 & 12 & 7 & 12 & 60 & 85.7 \\
\cline { 2 - 8 } & a close relative is a foreigner & 2 & 4 & 3 & 0 & 2 & 11 & 15.7 \\
\hline
\end{tabular}

INTERCULTURAL

INTERACTIONS AT MULTINATIONAL

Małgorzata Rozkwitalska Beata A. Basińska Michał Chmielecki Sylwia Przytuła Łukasz Sułkowski

Appendix 1. continue 